\title{
Alone in the universe: the landscapes of Jean Paul Lemieux
}

\section{Homage to Jean Paul Lemieux}

National Gallery of Canada

Oct. 22, 2004 - Jan. 2, 2005

Curated by the National Gallery of Canada

$\mathrm{I}$ $t$ is fitting that the National Gallery of Canada's centenary tribute to Jean Paul Lemieux (1904-1990) took place over the winter solstice. One of the most original and seminal modern artists in Quebec and Canada, Lemieux had a sombre, northern sensibility that was emphasized in this selection of over 50 paintings and drawings dominated by stark horizon lines, fields of snow and a feeling of immensity.

Born in Quebec City, Lemieux studied art in Montréal and Paris. The northern vision so evident in his art reveals the Canadian influences in his training, which included Edwin Holgate, a Group of Seven painter who taught Lemieux at the École des Beaux-Arts in Montréal. Another Montréal influence was Marc Aurèle de Foy Suzor-Côté, a major impressionist painter and sculptor whose workshop Lemieux frequented.

Lemieux's work was inspired by everyday life, and included portraits of his family, village scenes and the Quebec countryside, especially the Charlevoix region. Over the course of his career, Lemieux progressed from pictorial realism in the 1930s to develop a new type of representation in the fifties and sixties, emphasizing the structure of figurative space through highly simplified and refined paintings of landscape. This exhibit focuses on Lemieux's vision of the isolated human figure in vast surroundings, and explores the existential rela-

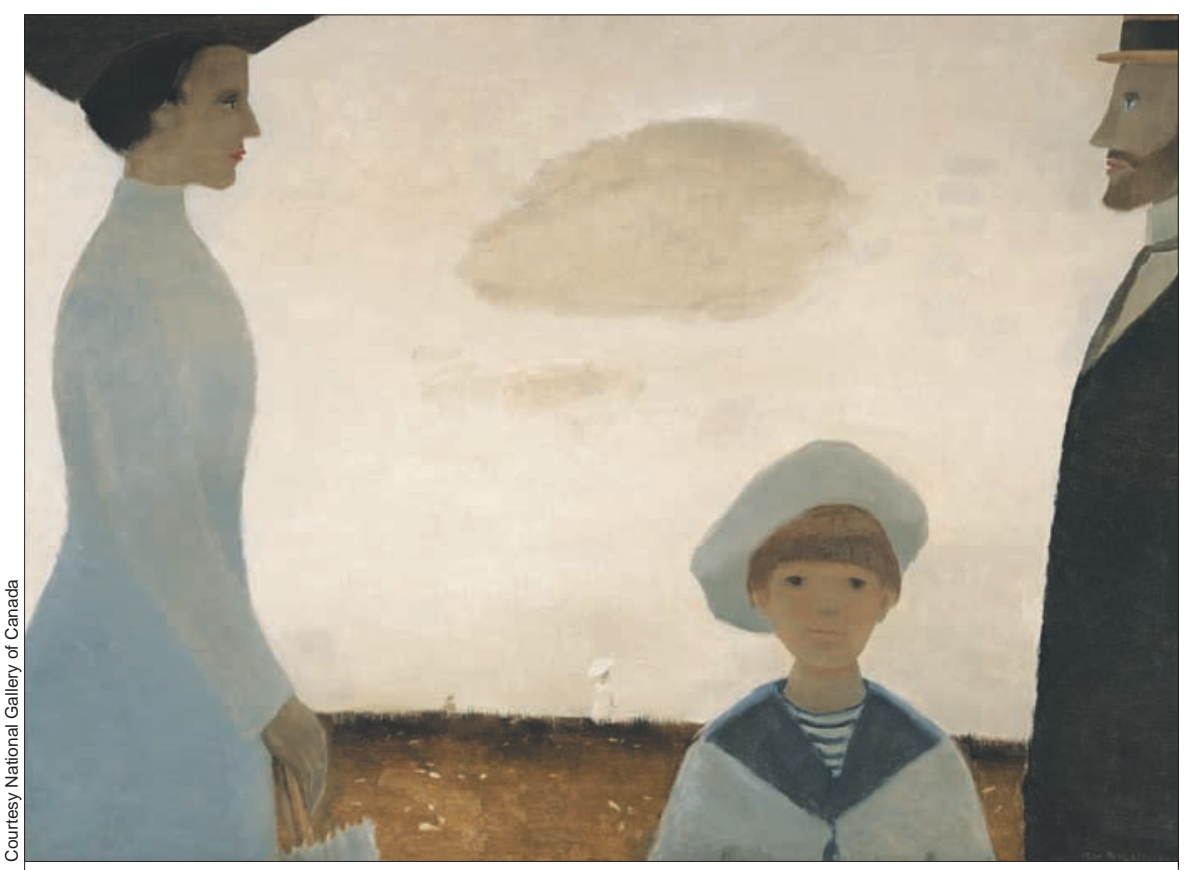

Jean Paul Lemieux, 1910 Remembered (1962). Oil on canvas. $108 \mathrm{~cm}$ x 148.8 $\mathrm{cm}$. Private collection.

tionship between human beings and the world. Lemeiux's unique vision, especially of landscape, came about during a period when abstraction had become almost universal in the art world. His faithfulness to his representational vision of the land and our relation to it rejuvenated landscape art in Canada and internationally.

Lemieux usually painted indoors, without using live models, and so his work came from imagination and memory, making it especially reflective of his personality, which was often described as sensitive and introverted.

In her introduction to the exhibi- tion, Lemieux's daughter, Anne Sophie, wrote: " $[\mathrm{H}]$ e liked to work alone, steeped in a silence that allowed him to hear his inner voice and to construct with brush and paint his inner world. This silence passed into his painting." From this inner world emerged a melancholy yet compassionate and sensitive vision that softened the edge of darkness in Lemieux's work.

One can catch a glimpse of Lemieux's nature in his subtle rendering of the priests in The Promenade of the Priests (1959), in which a group of Fathers wearing cassocks walk in the snow. Although these priests look

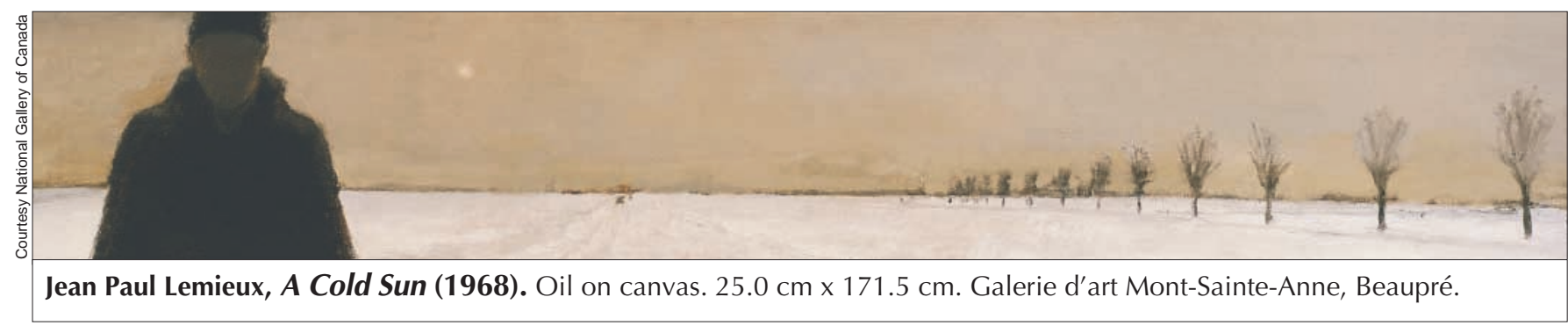




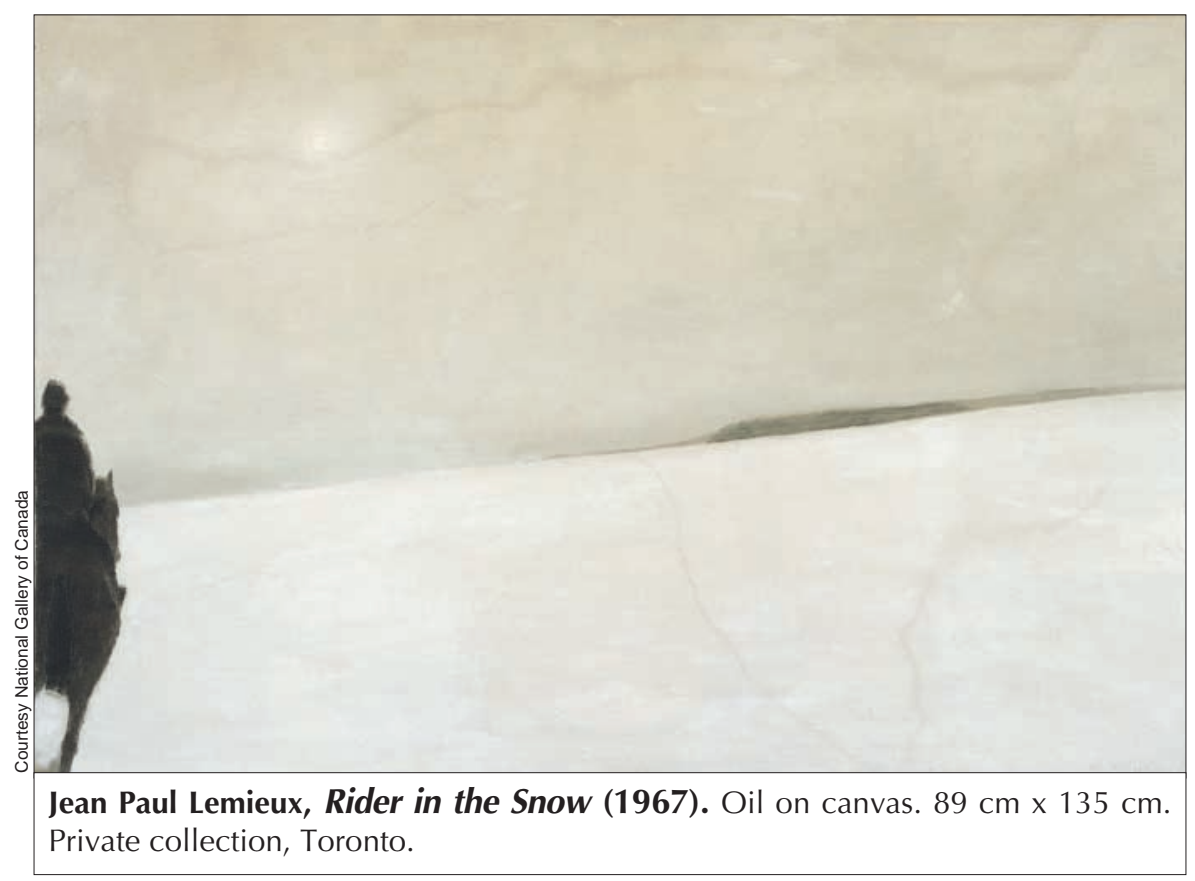

threatening, even severe, in their long dark robes, there is a hint of humour in this portrayal — the men look a bit like old-fashioned women wearing long dresses, socializing, perhaps even gossiping in the snow. This possibility, so at odds with the priests' respectability, shows Lemieux's understanding of their vulnerability and humanness.

A Cold Sun (1968), featured prominently in this exhibition, is classic Lemieux: it depicts a long horizon line, bare trees disappearing into the snowy distance, a smokestack, a road and the silhouette of a man alone. Although this oil painting does not have a lot of detail, it still has depth and richness. Lemieux's brushstrokes create a deep, heavy blanket of snow. Subtle shadows make up a snow-covered road that appears behind the man. Each bare tree on the right of the painting is alone, as the man is. There is an affinity between them. The winter light reveals a little of the man's face; his head tilts hope that his parents will stay together and the adult's knowledge that they did not. The painting is infused with a strange light, lending a golden, grainy quality that underscores a sense of loss.

Another important work in this exhibition is Lemieux's Self-portrait (1974). Here Lemieux represents himself at three stages: as a boy, as a young man in his twenties and as a seventyyear-old. These three figures stand together in a gallery where two of Lemieux's most famous paintings, Rider in the Snow (1967) and The Evening Visitor (1956) are displayed. These paintings within a painting depict figures alone in vast winter landscapes. They are windows out of the confined space of Lemieux's gallery into the immense space of Canada, and they are windows into Lemieux's inner life, where he stands alone in a mysterious environment that seems to extend into eternity.

Homage to fean Paul Lemieux succeeds in conveying Lemieux's compassionate perspective on the human condition, the passage of time and our human connection with landscape. All the same, visitors to the show would have benefited from seeing a few of Lemieux's early allegorical works, such as Lazarus (1941), and from a chance to view The Ursuline Nuns (1951), which shows the Cubist influences in Lemieux's work and marks the shift toward his characteristic simplified, minimalist style.

\section{Jennifer Dales}

Poet and freelance writer Ottawa, Ont.

Homage to Jean Paul Lemieux will travel to the Musée national des beaux-arts du Québec (Feb. 10 - Apr. 24, 2005) and then to the McMichael Canadian Art Collection in Kleinburg, Ont. (June 4 Sept. 5, 2005). 